\title{
Analysing Mechanism of an Economic Phase
}

\author{
Eizo Kinoshita, Takafumi Mizuno \\ Meijo University, Gifu, Japan
}

\begin{abstract}
In this paper, we define the thetical and antithetical phases of macroeconomy on a formal basis. And we formulate a bubble economy and its collapse by using these definitions. The concept of thetical and antithetical phases is introduced into economics by Kinoshita. In the course of discussion, we also make clear the difference between economic growth and bubble economy, while describing a mechanism of collapse of a bubble economy by using a simple macro-economic model instead of a specific model. As a result, we can analyse not only the state of thetical economy phase, and antithetical economy phase, but also bubble economy phase and bubble bursting economy phase. And we can describe mechanism of transitions among four economic phases.
\end{abstract}

Keywords: macroeconomics, thetical economy, antithetical economy, bubble economy, bubble bursting economy, economic phase

\section{Introduction}

According to Kinoshita, there are two phases in macroeconomy, and he named these phases thetical economy and antithetical economy (Kinoshita, 2009b, 2011a, 2012; Kinoshita, Suzuki, \& Sugiura, 2012). Kinoshita also identified corporate behavioral principles and governmental principles by applying the mechanism of primal and dual problem in linear programming (Kinoshita, 2009a, 2011a, 2012; Kinoshita, Suzuki, \& Sugiura, 2012), which led to bringing about the concept of thetical phase and antithetical phase in macroeconomy. While summarizing the relations between thetical phase and antithetical phase in "The Theorem of Duality in Macroeconomics", Kinoshita clarified duality in the role of market and that of government (Kinoshita, 2004, 2009a, 2011a, 2012; Kinoshita, Suzuki, \& Sugiura, 2012). Furthermore, Kinoshita described the processes of occurrence and collapse of a bubble economy from the angle of the above-mentioned phases (Kinoshita, 2010, 2011c).

In this paper, we define thetical and antithetical phases, using formulas which are not based on a specific model. We also define a bubble economy and its collapse by using the formulas. Furthermore, we show what these phases, or economic bubble and its crashing, signify by applying a simple model of macroeconomy.

\section{Notes}

In this paper, variable $Y$ denotes gross domestic product, variable $D$ represents total demand, variable $C$ indicates total consumer spending, variable $a$ expresses consumption coefficient, and variable $I$ signifies capital expenditure of economic entities (corporations, etc.) in macroeconomics.

The state of an economy is shown in $Y$-D space, and $Y$-axis expresses values of gross domestic product $(Y)$,

Eizo Kinoshita, Ph.D., Professor, School of Urban Science, Meijo University.

Takafumi Mizuno, Assistant, School of Urban Science, Meijo University.

Correspondence concerning this article should be addressed to Eizo Kinoshita, School of Urban Science, Meijo University, 4-3-3, Nijigaoka, Kani, Gifu, Japan. E-mail: kinoshit@urban.meijo-u.ac.jp. 
while values of total demand $(D)$ are also shown by $D$-axis. A state of an economy is expressed as a pair of values $Y$ and $D$ such as $(y, d)$ where $y$ signifies any value of $Y$ and $d$ denotes any value of $D$.

\section{Simple Model of Macroeconomy}

In this paper, we adopt a simple model of macroeconomy as a concrete model for the purpose of explaining abstract definitions, which is shown as:

$$
\begin{gathered}
D=C+I \\
C=a Y
\end{gathered}
$$

In this model, variable $a$ and variable $I$ are exogenous variables. We are interested in demonstrating how these exogenous variables affect the endogenous variable $Y$.

\section{Thetical Phase and Antithetical Phase}

Kinoshita proposed two economic phases in macroeconomy, or thetical phase and antithetical phase (Kinoshita, 2009b, 2011a, 2012; Kinoshita, Suzuki, \& Sugiura, 2012). These phases are described as subsets of $Y$ - $D$ space. Thetical phase is a set of points in $Y$-D space:

$$
\text { Thetical }\left(y_{0}\right)=\left\{(y, d) \mid y>y_{0} \text { and } d \geq y\right\}
$$

Antithetical phase is a set of points in $Y$ - $D$ space:

$$
\text { Antithetical }\left(y_{0}\right)=\left\{(y, d) \mid y<y_{0} \text { and } d \leq y\right\}
$$

Elements of these subsets are affected by $y_{0}$ whose supply is equal to an economic equilibrium point, or a full employment income. In the simple model of macroeconomy, thetical phase and antithetical phase are represented by two triangle areas shown in $Y$-D plane (see Figure 1).

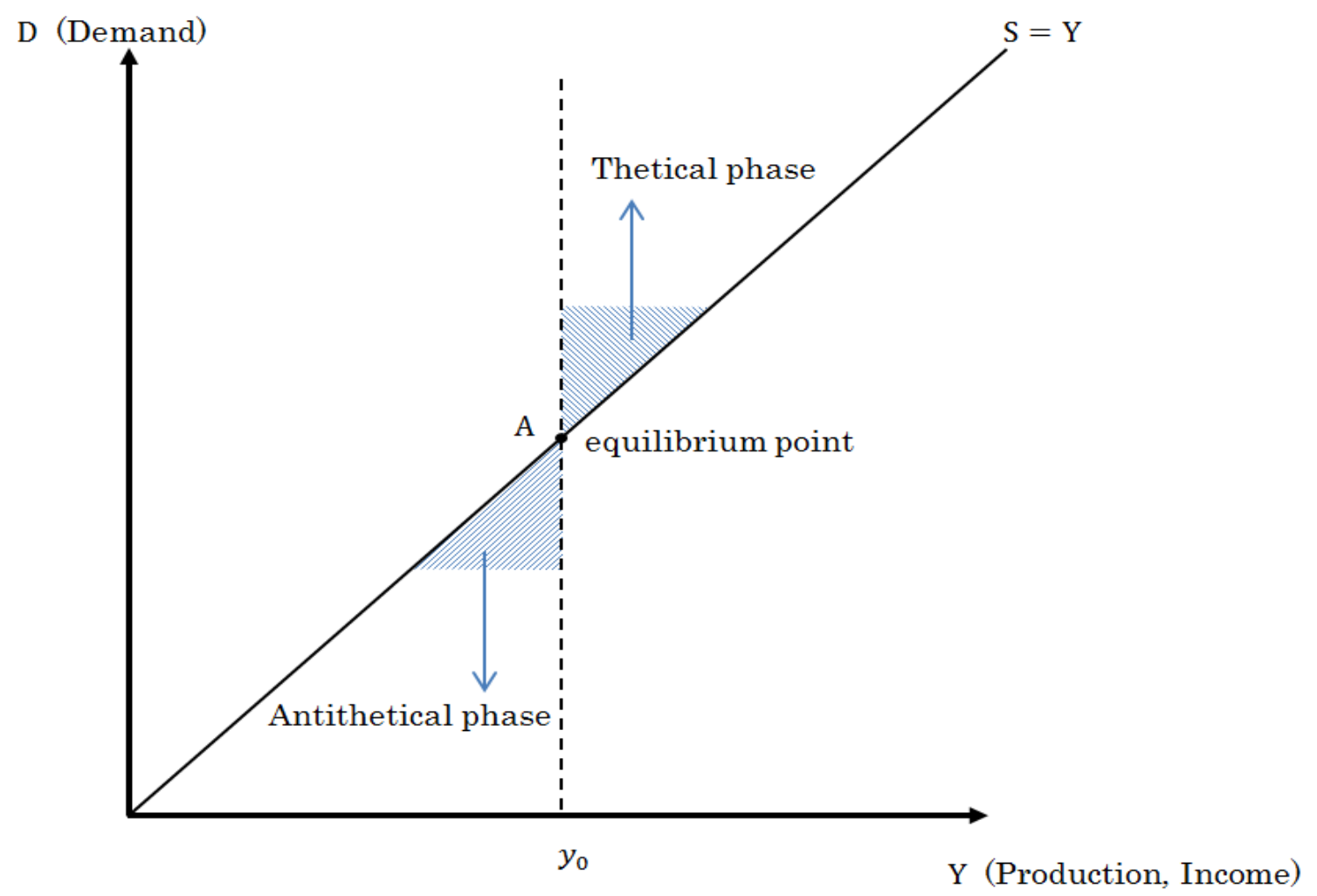

Figure 1. Thetical phase and antithetical phase in economic space in the simple model of macroeconomy. $Y$ denotes gross domestic product, $D$ signifies demand, and $S$ represents supply. These phases have a relationship of duality. 
If a state $(y, d)$ is in a thetical phase, supply is defined as follows:

$$
Y=C+I
$$

The Say's law is applicable in this case.

While, if a state $(y, d)$ is in an antithetical phase, supply holds a relationship as follows:

$$
Y \geq C+I
$$

The principle of effective demand comes into play in this case.

\section{Bubble Economy}

We define a bubble economy as follows: If a state $(y, d)$ is in a thetical phase and the value $\left.\frac{\partial Y}{\partial I}\right|_{(y, d)}$ is sufficiently large, the state $(y, d)$ is in a bubble economy. And we define the bubble bursting as follows: When there can be seen a partial change, or $\frac{\partial Y}{\partial I}$ from value $\frac{\partial Y}{\partial I}>0$ to value $\frac{\partial Y}{\partial I}<0$, in any state in a bubble economy.

We explain a mechanism of the bubble bursting shown by the simple model of macroeconomy through variations of consumption coefficient $a$. If a state is in a thetical phase, in the simple model of macroeconomy, we obtain the following relationships:

$$
\begin{aligned}
& \frac{\partial Y}{\partial I}=\frac{\partial C}{\partial I}+1 \\
& \frac{\partial C}{\partial I}=a \frac{\partial Y}{\partial I}
\end{aligned}
$$

Now, we deduce as follows:

$$
\frac{\partial Y}{\partial I}=\frac{1}{(1-a)}
$$

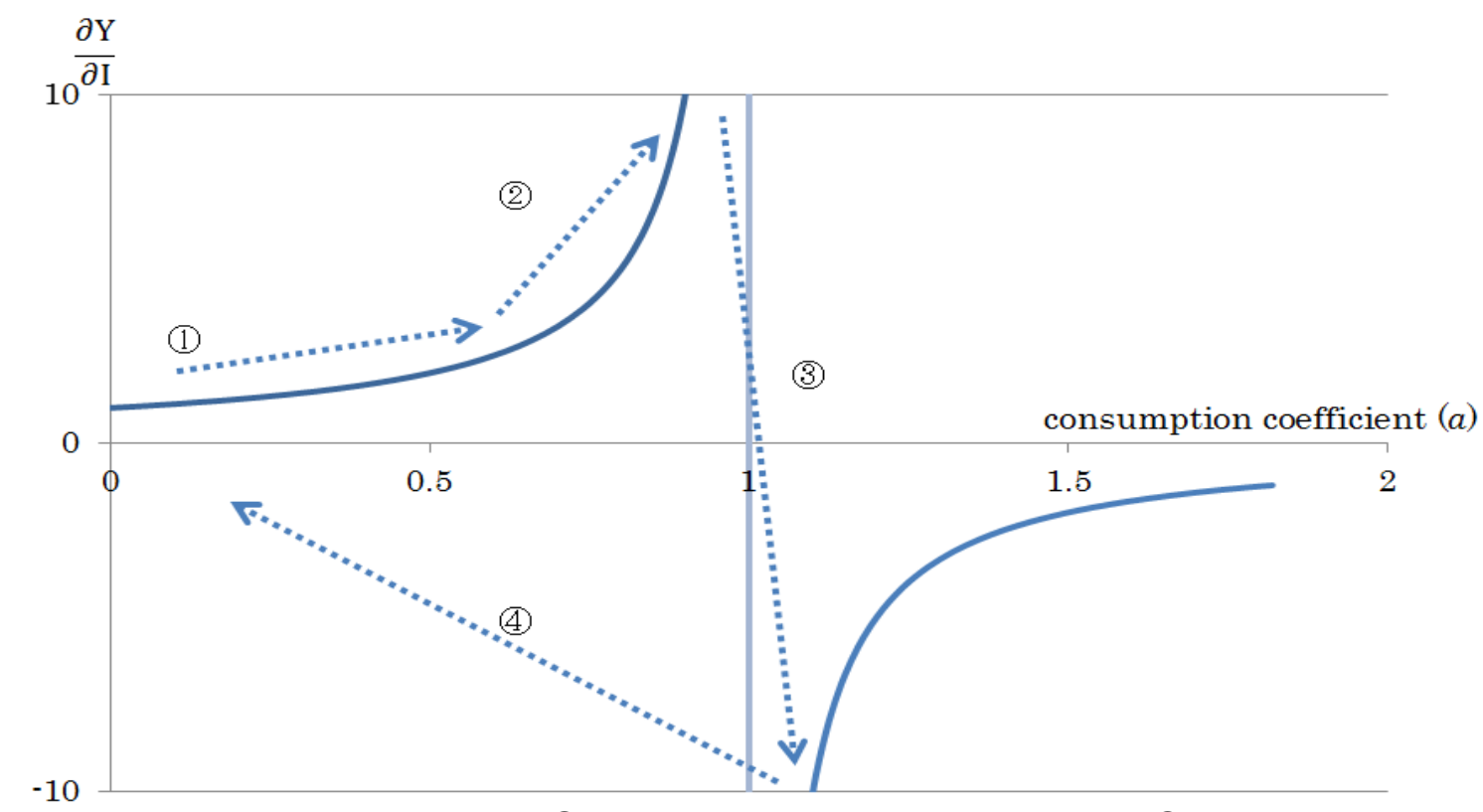

Figure 2. Mechanism of bubble bursting: (1) a state of economy is in a thetical phase; (2) a state is in a bubble economy; (3) bubble bursting; and (4) a state of economy is in an antithetical phase. 
Thus, we can describe a mechanism of the bubble bursting through the behavior of exogenous variable $a$ : (1) first, an economy of real world is demonstrated in a thetical phase economy; (2) the consumption coefficient $a$ increases and comes close to 1, and the state is in a bubble economy; (3) the consumption coefficient $a$ surpasses 1 , resulting in bubble bursting $\left(\frac{\partial Y}{\partial I}>0 \rightarrow \frac{\partial Y}{\partial I}<0\right)$; and (4) the value $\frac{\partial Y}{\partial I}$ is sharply down, and an economy of real world is found to be in an antithetical phase.

\section{Discussions}

In our definition, a bubble economy is different from economic growth. A concept of economic growth based on the simple model of macroeconomy is demonstrated in Figure 3. When corporate investment increases $(\Delta \mathrm{I})$, the equilibrium point moves from $A$ to $A^{\prime}$, heading toward the expanded equilibrium. When corporate investment increases to $I_{1}$, then the economic equilibrium point moves to $A_{1}$. As a result, the economy expands more, which is accompanied by an increase in consumption. When corporate capital expenditure grows to $I_{2}$, the economic equilibrium point moves to $A_{2}$, spurring the economy to grow further. During the process of the transition of economic equilibrium points $A \rightarrow A^{\prime} \rightarrow A_{1} \rightarrow A_{2}$, the consumption coefficient $a$ is constant in the demand function.

$$
D=a Y+I
$$

When the consumption coefficient $a$ is 0.9 in the simple model, for instance, the multiplier effect is expressed as follows:

$$
\frac{1}{(1-a)}=\frac{1}{(1-0.9)}=10
$$

This means that economic growth with the multiplier effect is 10 times (see Figure 3). We define this type of economic expansion as "economic growth". We hope readers will remember this definition whenever it is mentioned in this paper.

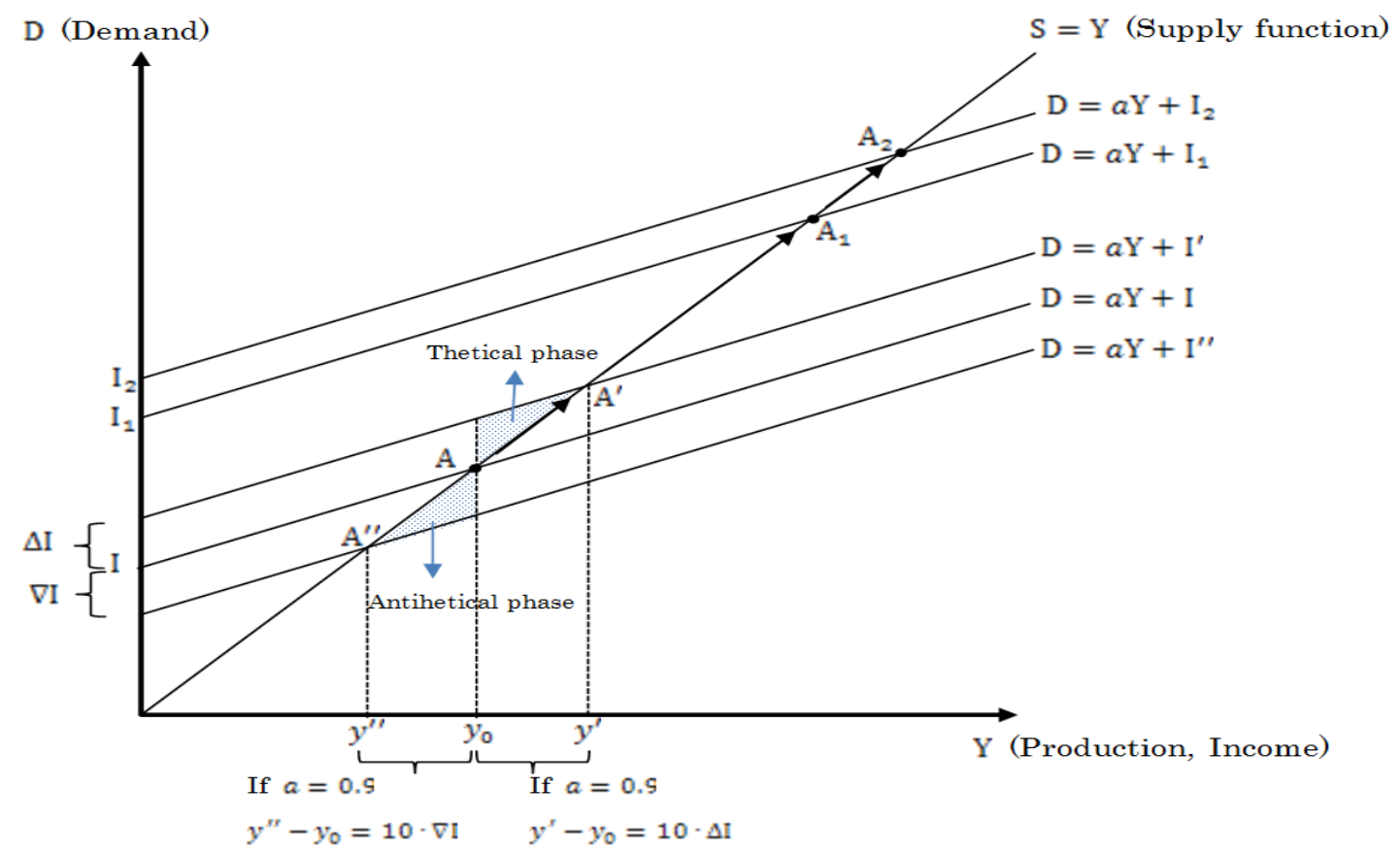

Figure 3. Concept of economic growth. I represents investment and $a$ signifies consumption coefficient. 
An increase in private sector demand, during the process of economic growth, may prompt not only companies to expand capital expenditure, but also individual consumers to engage in speculation. In the United States, for example, even a shoeshine boy purchased stocks for speculation during the 1920s. In Japan, housewives, elderly people, and even students engaged in speculation during the so-called Heisei Bubble of the early 1990s. The housing bubble of the United States occurred as an increasingly large number of low-income earners started taking out sub-prime loans after 2005, before U.S. house prices began their steep decline, which triggered the sub-prime crisis in 2008. It was another example of speculative behavior by common folks in the U.S.. In such a state, the consumption coefficient $a$ in the demand function $D=a Y+I$ is infinitely close to 1. As a result, its economic effect, or multiplier effect, represented by $\frac{1}{(1-a)}$ in the simple model of macroeconomy, grows without limit. Under such circumstances, the economy expands infinitely, even without an increase in corporate capital expenditure. Our definition of a bubble economy in section three expresses such a state without abnormally high investment effect. We demonstrated a bubble economy in Figure 4. The economy expands when the consumption coefficient of individual consumers is closer to 1 , even without an increase in corporate investment in facilities. And the economic equilibrium point moves from $A^{\prime}$ to $A_{1}$, and to $A_{2}$. This is the state of a bubble economy.

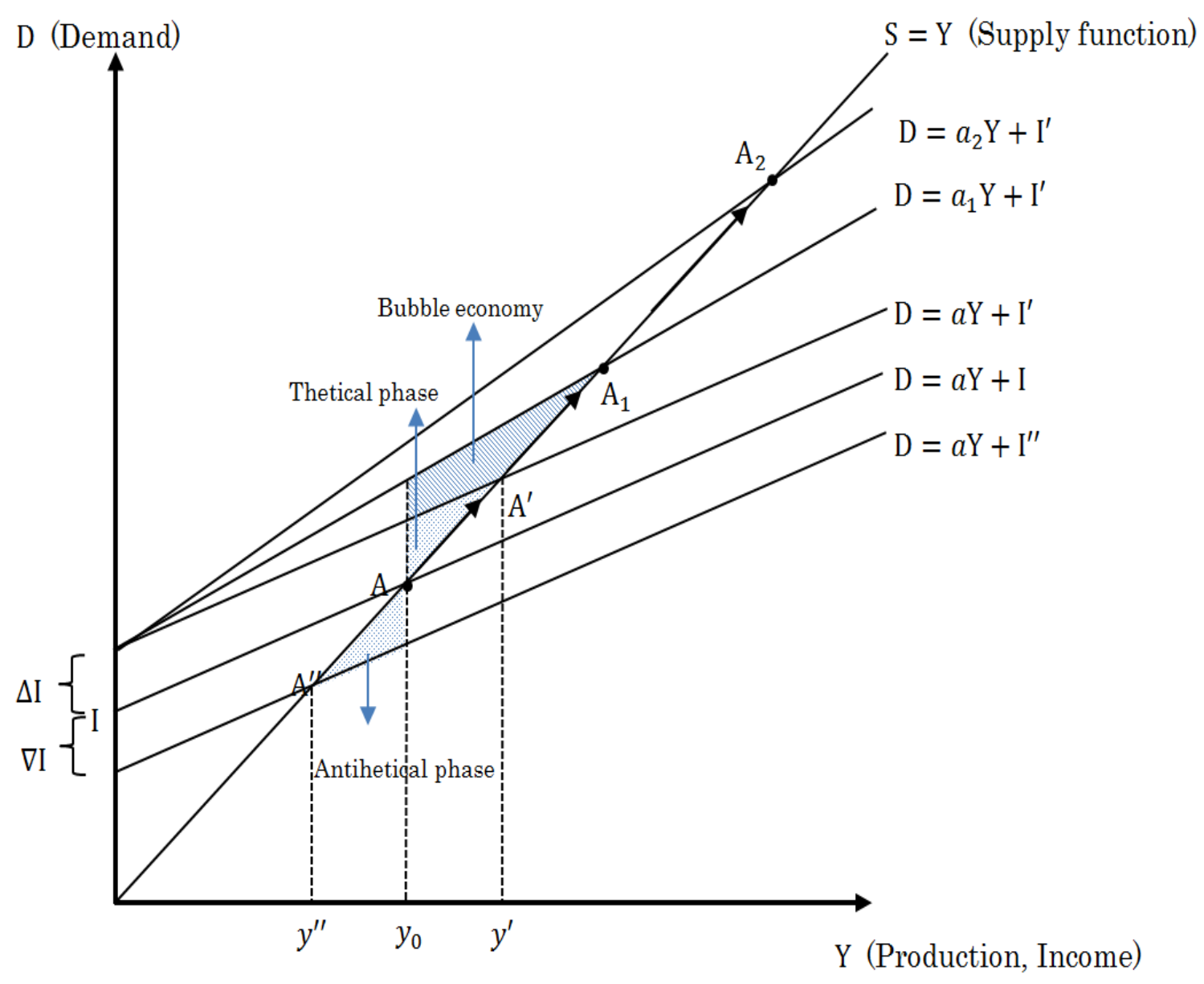

Figure 4. Bubble economy. 


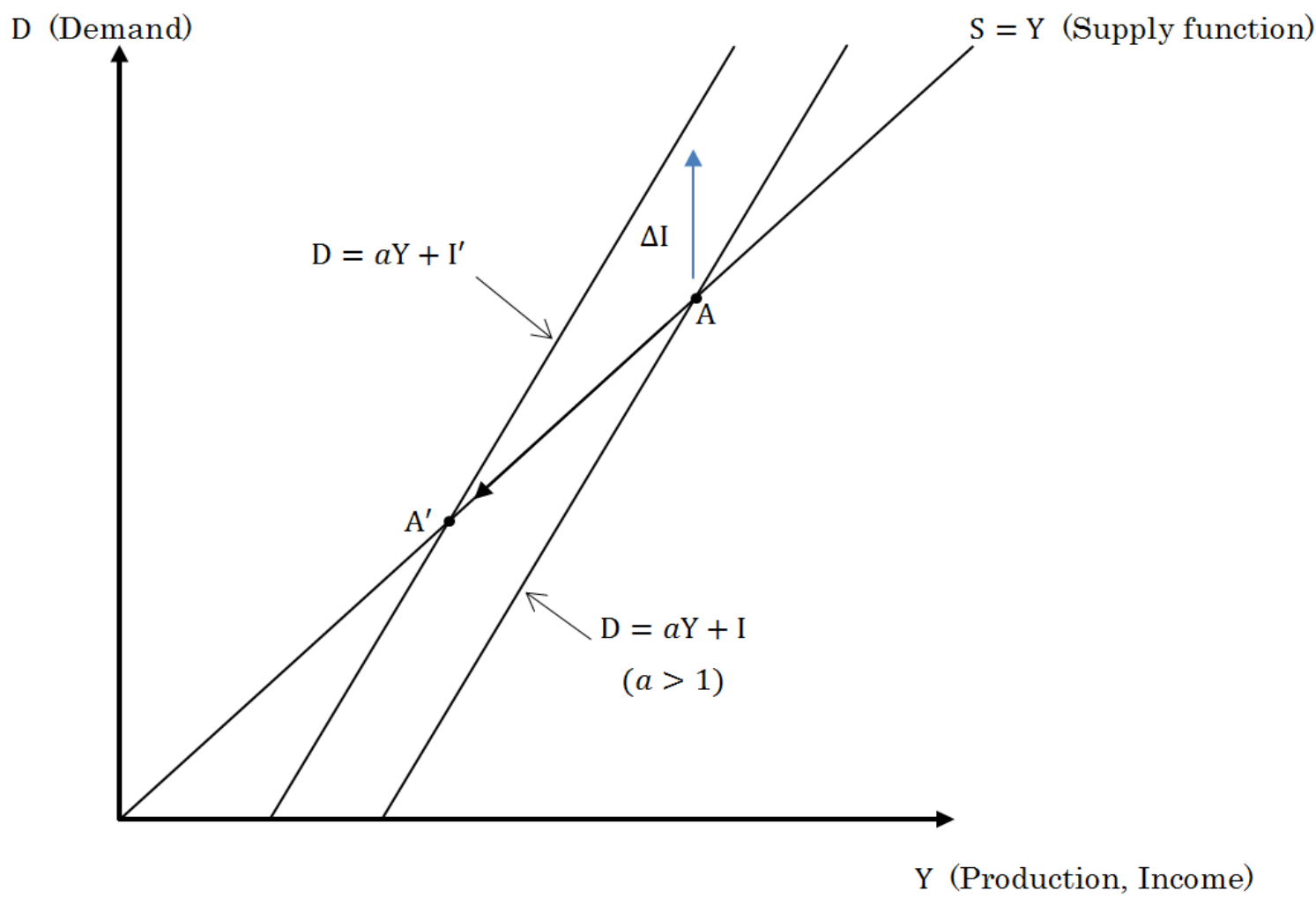

Figure 5. Mechanism of occurrence and collapse of a bubble economy.

A bubble economy is often mistaken to be "an outstanding state of economy". History shows that once an individual gets a forbidden state of "a bubble economy", his or her enthusiasm for speculation tends to be accelerated. During "the Tulip mania" in the first half of the 17th century in the Netherlands, the fad became so excessive that the price of a single tulip bulb rose as high as the price of a house. However, once the consumption coefficient of this "forbidden state of bubble" becomes marginally above 1 , the bubble bursts. The process is shown in Figure 5.

If the consumption coefficient $a$ is 1.1, for instance, in the simple model, it turns out to be as follows:

$$
\begin{aligned}
& Y=C+I \\
& C=1.1 Y
\end{aligned}
$$

The solution for the simultaneous equations is as follows:

$$
Y=-10 I
$$

It means that when consumption coefficient grows larger than 1 , and corporate capital expenditure increases by a unit $\Delta \mathrm{I}$, the economic equilibrium point falls sharply, and the bubble bursts as shown in Figure 5 . The economic equilibrium point moves from $A$ to $A^{\prime}$ in this case. Once people come to recognize this downturn, they tend to refrain from economic activities, which include not only speculation but also consumption. As a result, the overall consumption of the economy shrinks back, and the consumption coefficient marks less than 1 .

After the collapse of a bubble economy, consumption activities return to normal. As a result, however, the economy suffers a great lack of demand as shown in Figure 6. We define this state "collapse of a bubble economy" as is shown in section three, in which we described the bubble bursting. 


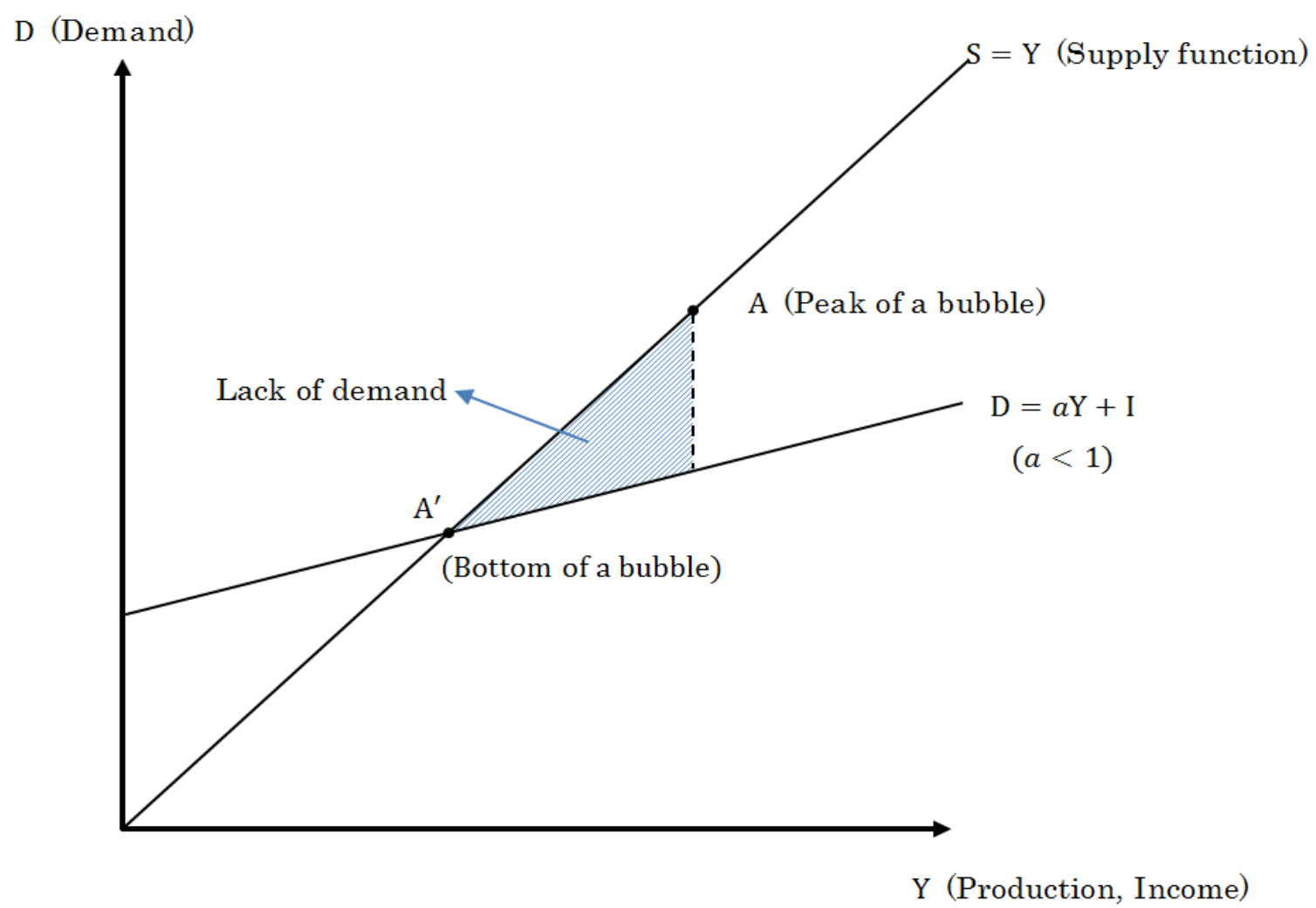

Figure 6. Lack of demand.

As shown in Figure 6, private-sector demand for capital falls sharply. Companies stay away from capital expenditure because investment efficiency goes down to dire levels. In other words, because the value of assets purchased on credit during the bubble period collapses, the efficiency of investment drops below the market interest rate for corporations with debt. As a result, companies discontinue investing in facilities, and shift their business priorities from profit maximization to debt minimization. In this state, macroeconomy moves from thetical phase to antithetical phase, with corporate goal shifting from profit maximization to debt minimization. Meanwhile, due to low investment efficiency, companies stop borrowing money from banks to make investments. Instead, they become intent on paying down debt. As a result, money is tucked away in the banking system.

\section{Conclusions}

We define thetical phase and antithetical phase in macroeconomy as subsets of economic space. These are models based on independent definitions. Under these definitions, we describe a bubble economy and the bubble bursting through investment efficiency $\frac{\partial Y}{\partial I}$. In the simple model of macroeconomy, since the investment efficiency is expressed as an inverse proportionality of consumption coefficient, we can describe a bubble economy and the bubble bursting through the variations of consumption coefficient. Also, in the simple model, bubble bursting only occurs when the consumption coefficient $a$ surpasses 1 . 


\section{References}

Kinoshita, E. (2004). Two laws that dictate economy. Tokyo: Denki Shoin.

Kinoshita, E. (2009a). A proposal of prime and dual problems in macroeconomics (p. 120). Proceedings from 23th European Conference on Operational Research. Bonn.

Kinoshita, E. (2009b). Why economics studies make mistakes-Two economics principles overlooked by Marx And Keynes. Tokyo, Japan: Tokuma Shoten.

Kinoshita, E. (2010). Why bubble economy occurs and crashes? (p. 37). Proceedings from 24th European Conference on Operational Research. Lisbon.

Kinoshita, E. (2011a). A proposal of primal and dual problems in macro-economics. Journal of China-USA Business Review, $10(2), 115-124$.

Kinoshita, E. (2011b). Globalization or Isolation?_-Ricardo’s model. Journal of Chinese Business Review, 10(10), 1-9.

Kinoshita, E. (2011c). Why bubble economy occurs and crashes?-Repeated history of economic growth and collapse. Chinese Business Review, 10(2), 111-120.

Kinoshita, E. (2012). A proposal of thetical economy and antithetical economy-Mechanism of occurrence and collapse of bubble economy. Journal of Business and Economics, 3(2), 117-130.

Kinoshita, E. (2013). Verifying ricardo’s model—Whether TPP is right or wrong?. Journal of Mathematics and System Science, 3 , 31-40.

Kinoshita, E., Suzuki, A., \& Sugiura, S. (2012). A survey of kinoshita theory in macro-economics—Primal problem and dual problems in macro-economics (79-82). Bulletin of Research Institute of Meijo University, No. 17. 